macular region appears normal. At the periphery of the fundus extending from " six o'clock below temporally and superiorly to two o'clock" above there is a white band of choroidal scarring some two D.D. wide situated about two D.D. behind the ora. There is considerable pigmentation of this band in the lower temporal quadrant, but little elsewhere. Over the remainder of the periphery the fundus appears normal.

The patient is able to carry on his duties as a priest. A long. letter he has written shows no evidence of visual inability.

\title{
Summary
}

The main features of the case are:-

1. The large size of the tear; more than half the circumference of the retina.

2. The folding in half of the detached retina so that its posterior surface was facing anteriorly.

3. The replacement of the retina by ordinary operation, assisted perhaps by gravity, but not by retinal hooks or other devices.

4. The degree of recovery of vision after complete and wide separation of the macula for over a week.

My thanks are due to Mr. Freeman Heal for his examination notes, and for his permission to publish this case; to Mr. Shapland, under whose care the case was admitted to Moorfields, for permission to send the patient to Utrecht; and lastly to Professor Weve for his notes and diagrams of the operation, and for its successful result.

\section{A NEW DARK ADAPTATION TESTER}

\author{
BY \\ SIMON YUDKIN \\ FROM THE DEPARTMENT OF PATHOLOGY, UNIVERSITY \\ COLLEGE HOSPITAL, LONDON
}

IN view of the importance of night-blindness in present circum. stances it is felt that the following description of an instrument which combines many advantages with comparative simplicity may be of some use.

The dark adaptation tester* as devised by R. T. M. Haines (1) and investigated and used by the writer, is an instrument designed to test the rate at which the eye recovers its power to distinguish a faintly lighted object following a period in which it has been subjected to strong illumination, and also to discover the threshold of visibility after complete adaptation.

* Manufactured by Crookes' Laboratories, London. 


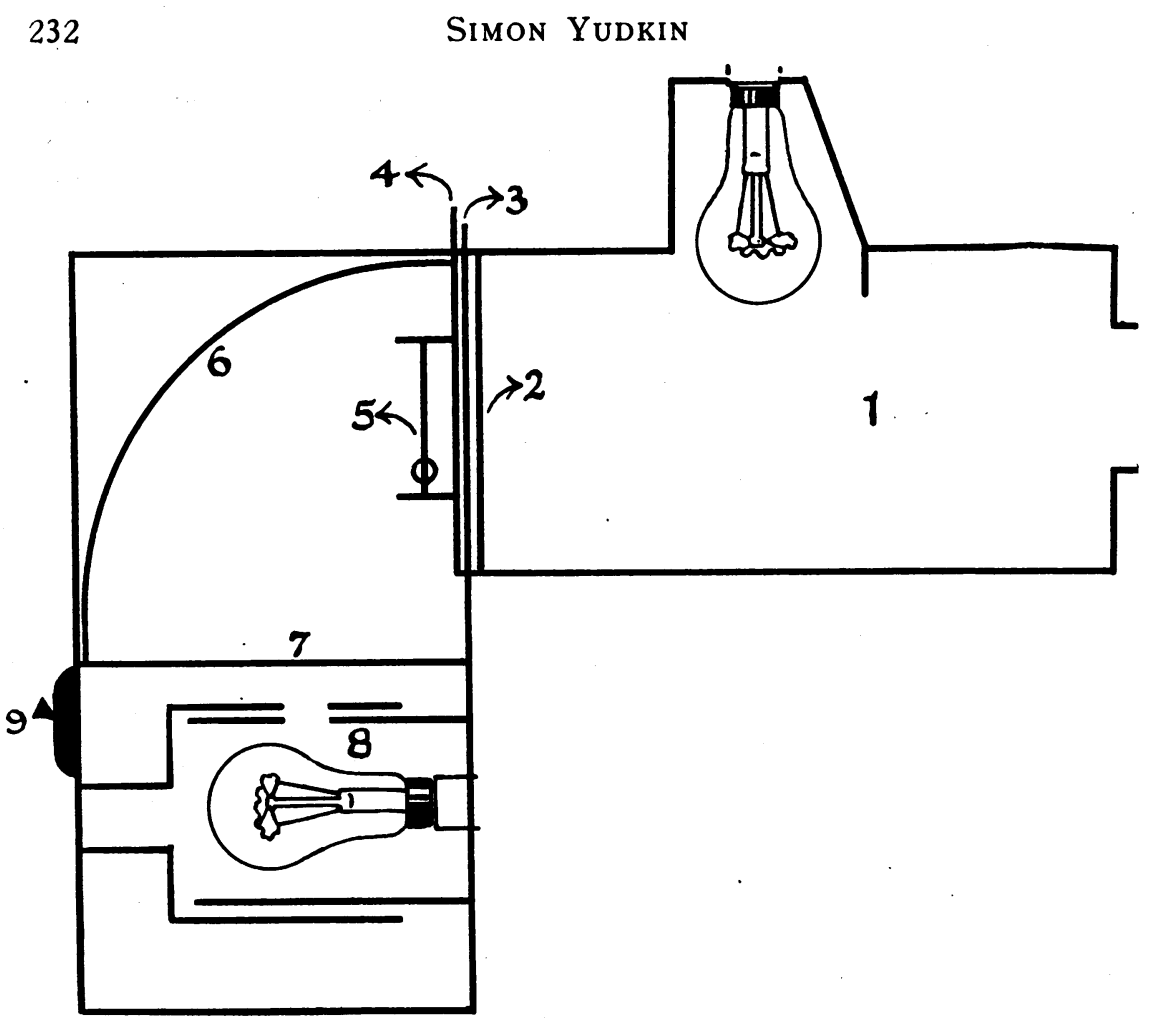

Fig. 1.

The instrument consists of the following parts. (See Fig. 1).

1. Eye tube with light and face piece. The light is an ordinary 60 -watt lamp and gives a brightness of about 700 millilamberts. ${ }^{1}$

2. Silhouette arrow plate, the arrows being cut out of the metal plate and when illuminated from behind, forming the test object, which subtends an angle of $6^{\circ}$ on the retina.

3. Fixed "Polaroid" screen with scale.

4. Moving "Polaroid" screen with finger post. When the finger post is opposite a figure on the scale it indicates the percentage of light transmitted by the two screens.

5. Light and dark neutral glasses with operating handle; the transmission of the two glasses is 4 per cent. and 0.1 per cent. (Ratio 40-1).

6. Reflector.

7. Diffuser.

8. Test object illuminating lamp with adjustable aperture. This aperture is specially set and should not be altered. The test lamp is a 25 -watt lamp " aged" for 100 hours.

9. Three-ivay switch.

1. One millilambert corresponds to illumination of 1.076 foot candles. 


\section{Carrying out the Test}

No preliminary dark adaptation is necessary unless the subject has been out in very strong light, e.g., snow or strong sunlight. "Bleaching" is carried out for seven minutes, the subject being seated at a comfortable height and instructed to keep the eyes moving so that the whole retina is "bleached." Eyes should not be closed but blinking is immaterial.

At the end of seven minutes "bleach" the tube light is extin. guished and the test object light is put on. The finger post is in the " 75 " position and the light neutral glass in place. The arrow plate is turned from the "blank" position which it occupied during the "bleach" to any of the silhouette arrows. The subject is instructed not to fix his gaze where he thinks the arrow will be, but to let the eyes wander so that the arrow will appear without any straining on his part. As soon as the subject can state definitely in which direction the arrow is pointing, the time is noted, the finger post moved down to " 50 " and another arrow placed into position. As soon as the subject can see the fresh arrow the process is repeated, always diminishing the illumination. After reaching " 3 " on the light glass the dark glass is put in, the finger post put at " 75 " and the process repeated. This is continued for 35 minutes, but after 15 minutes it is useful to confirm the subject's statement by showing him two arrows successively at the same illumination. The time for the first correct reading is the one recorded.

- A curve connecting time and $\log _{10}$ relative illumination is constructed. Should this curve lie wholly or mainly above and to the right of the standard curve (see Fig. 2), vitamin A deficiency should be suspected.

\section{Notes}

1. A well shaded torch light is needed for the operator.

2. Should new lamps be required the one in the "bleaching" tube can simply be replaced but the test object light should be tested on a person with known dark adaptation.

3. The actual illumination of the arrow at each mark on the scale varies somewhat from instrument to instrument, but each instrument is calibrated so that the curves obtained may be compared with the normal curves which have been obtained on a photometrically standardized model.

\section{Discussion}

Hecht and Mandelbaum (10) stated that in designing the perfect dark adaptation test the following facts must be given :-

(a) Duration and brightness of the pre-adapting light.

(b) Duration, colour, size and retinal location of test object.

(c) Size of pupil. 
Each of these factors has been investigated from the point of view of its necessity in a clinical instrument and is discussed below.

The apparatus has the following advantages: -

1. Both "bleaching" and "testing" are carried out on the same instrument.

2. The "bleaching" tube ensures that the whole retina is " bleached."

3. The test object can be varied so that the subject's statements can be verified.

4. The "Polaroid" screens allow fine adjustments of the illumination.

In carrying out the test a long and intense "bleach" is given. This ensures that the "macular" (9) part of the curve (Fig. 2) is more marked and also eliminates any effect due to the subject's state of adaptation immediately preceding (2). If, however, the subject has undergone abnormal "bleaching" (e.g., strong sunlight or snow), he should be put for half an hour in a darkish room before beginning the "bleach."

The test is continued for 35 minutes in the dark. All tests which are carried out for short periods $(1,3,4,5,6)$, test the dark adaptation during the "macular" period only. Although this does change with vitamin A deficiency $(7,8)$ there is very little alteration and it is sometimes found that this part of the curve may be within the normal range while the latter part is quite abnormal and ends on a much higher threshold.

There is no fixation spot $(9,10)$; on the contrary the subject is told to move his eyes so that he may find the most sensitive part of the retina for himself. The spot does increase the accuracy of the curves slightly but only at the expense of the comfort of the subject, who finds it exhausting to stare at one point for such a long time. Even without the spot the normal variation is not large. Towards the end of the test, the arrow is often seen for a moment and then missed as the eye is moved and a less sensitive part of the retina is focused. It is therefore best to use two successive arrows and to record the time for the first correct reading. (See instructions).

The test light is left on throughout the test. The effect of having a "flash" test light of different durations with a fixation spot was tried but was found to complicate the test without increasing the accuracy of the curves to any notable extent.

The colour of the test light is greenish (9) due to the "Polaroid" screens but it remains the same throughout since the colour of the transmitted light only changes when the screens are almost completely crossed.

It was not found necessary to constrict the pupils by physostigmine (11). Superficial ophthalmological examination should be carried out in any case. Both eyes are used for the test as the 
difference between them is very small or non-existent and the test is thereby made more comfortable. Spectacles of strength greater than +3 D. should not be worn for the test.

Voltage fluctuations on the ordinary supply are of no importance. The instruments are calibrated on a 240-volt circuit.

The curve is plotted with time in minutes on the horizontal co-ordinate and $\log _{10}$ brightness on the vertical co-ordinate. The brightness is measured in micro-microlamberts (lamberts $\times 10-12$ ), in accordance with most American articles on the subject. $(7,8,9$, $10,11,12)$. The normal range of dark adaptation as carried out in this way is given in Fig. 2. This curve has been constructed from the results of over 150 tests on about 100 normal subjects, the

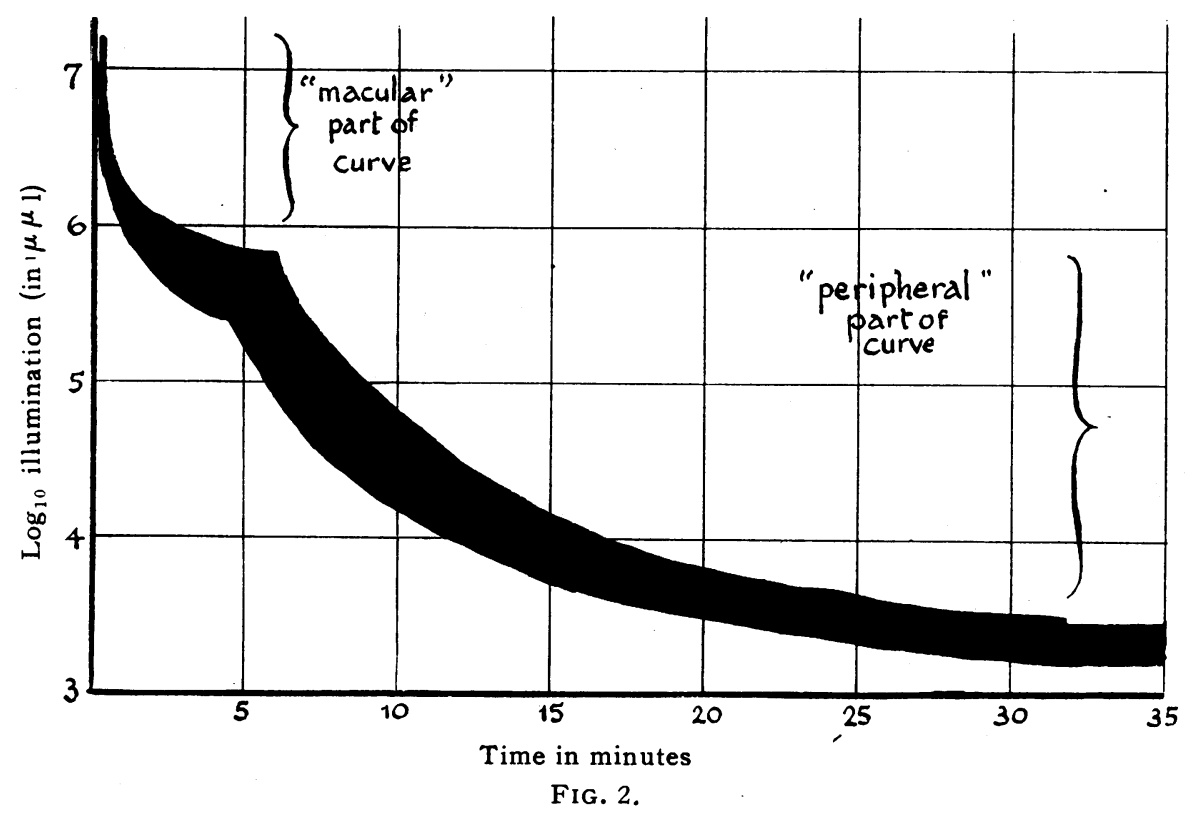

normal being such that no improvement occurs with large doses of vitamin A. Abnormal curves can also be brought within the normal range by giving the subject large doses of vitamin $A$. It will be noticed that the range is approximately the same as that found by Hecht and Mandelbaum (10) and Patek and Haig (12).

\section{Rapid testing of large groups}

Large numbers of people can be rapidly tested as follows:-A group of subjects (up to 15 in number) is put into a dark room. At the end of 30 minutes each one moves in turn to the instrument and the "minimum visible light" is determined. Each test takes less than one minute and if another group enters the dark room about half way through the dark adapting period, a continuous stream of subjects can be tested. Although the last of the group 
may have been in the dark for as much as 45 minutes the "minimum visible" does not change after 30 minutes. It is to be noted that each subject spends at least 30 minutes in the dark, but the operator can test 50-60 people in an hour with-sufficient accuracy for large surveys.

A full report on the use of this instrument with night-blind subjects will be published shortly.

I would like to thank Professor. C. R. Harington for the laboratory and other facilities for this work.

\section{Summary}

A new instrument for measuring dark adaptation is described.

Its method of use and advantages over other instruments are discussed.

The normal range of dark adaptation is given.

A rapid method for large surveys is appended.

\section{REFERENCES}

1 Haines, R. T. M. (1938).-Trans. Ophthal. Soc. U.K., Vol. LVIII, p. 103.

2. Thomson, A. M. et al. (1939).-Brit. Jl. Ophthal., Vol. XXIII, p. 461.

3. Jeans, P. C., Blanchard, E. and Zentmire, Z. (1937).-Jl. Amer. Med. Assoc., Vol. CVIII, p. 451.

4. Harris, L. J. and ABBaSSY, M. A. (1939).-Lancet, Vol. XII, p. 1299.

5. PetT (1939).-Jl. Lab. and Clin. Med., Vol. XXV, p. 149.

6. DitchBURN, R. W. (1939).-Nature, Vol. CXLIII, p. 2-5.

7. Wald, G., Jeghers, H: and Arminio, J. (1938).-Amer. Jl. Physiol., Vol. CXXIII, p. 732.

8. Booher, L. E., Callison, E. C. and Hewiston, E. M. (1939).-Jl. Nutrit., Vol. XVII, p. 317.

9. Неснт, S. (1937).-Physiol. Rev., Vol. XVII, p. 239.

10. Hecht, S. and Mandelbaum, J. (1939).-Jl. Amer. Med. Assoc., Vol. CXII, p. 1910.

11. Feldian, J. B. (1938).-Arch. Ophthal., Vol. XIX, p. 882.

12. PATEK, A. J. and HAIG, C. (1939).-Jl. Clin. Invest, Vol. XVIII, p. 609.

\section{ANNOTATION}

\section{Eyes on the Road}

The heavy toll of life from accidents on the highways of this country has long been a grave public scandal and one that becomes no lighter despite the reduction of private motor traffic. Recently there have been 300 accidents a day from military vehicles alone.

The examination of men called up for the Army has afforded a revelation in the ocular defects of those whose civil occupation is that of driving lorries and other vehicles. The worst of these, passed by civilian medical boards, have too low a visual standard to be accepted by combatant units and so are posted to such corps as the Royal Army Service Corps and Royal Army Ordnance Corps where their civilian qualifications as lorry drivers are accepted and they are allocated to these tasks. Fortunately the necessity for 